\title{
Use of electronic medical records and quality of patient data: different reaction patterns of doctors and nurses to the hospital organization
}

\author{
Mattijs S. Lambooij ${ }^{*}$, Hanneke W. Drewes ${ }^{2}$ and Ferry Koster ${ }^{3}$
}

\begin{abstract}
Background: As the implementation of Electronic Medical Records (EMRs) in hospitals may be challenged by different responses of different user groups, this paper examines the differences between doctors and nurses in their response to the implementation and use of EMRs in their hospital and how this affects the perceived quality of the data in EMRs.

Methods: Questionnaire data of 402 doctors and 512 nurses who had experience with the implementation and the use of EMRs in hospitals was analysed with Multi group Structural equation modelling (SEM). The models included measures of organisational factors, results of the implementation (ease of use and alignment of EMR with daily routine), perceived added value, timeliness of use and perceived quality of patient data.

Results: Doctors and nurses differ in their response to the organisational factors (support of IT, HR and administrative departments) considering the success of the implementation. Nurses respond to culture while doctors do not. Doctors and nurses agree that an EMR that is easier to work with and better aligned with their work has more added value, but for the doctors this is more pronounced. The doctors and nurses perceive that the quality of the patient data is better when EMRs are easier to use and better aligned with their daily routine.

Conclusions: The result of the implementation, in terms of ease of use and alignment with work, seems to affect the perceived quality of patient data more strongly than timeliness of entering patient data. Doctors and nurses value bottom-up communication and support of the IT department for the result of the implementation, and nurses respond to an open and innovative organisational culture.
\end{abstract}

Keywords: Electronic medical records, Health personnel, Hospital, Health services, Implementation process, Quality of patient data

\section{Background}

Electronic Medical Records (EMRs) are widely implemented in health care organisations, and much is known about factors affecting implementation processes. Despite the expected benefits of EMRs [1-3] the adoption of EMRs proceeds slowly $[3,4]$. The body of literature of implementation of EMRs is considerable and many

\footnotetext{
*Correspondence: mattijs.lambooij@rivm.nl

${ }^{1}$ Department Quality of care and health Economics, National Institute for Public Health and the Environment (RIVM), PO Box 13720 BA Bilthoven, The Netherlands

Full list of author information is available at the end of the article
}

competing theories and models exist. In many of those theories and models, the organisation, the type of innovation or technology and the user [1,5-9] play a role. Evidence on organisational factors affecting innovation processes in health care organisations is mixed [10]. Some studies find positive associations [11] and others find little or no effect on the innovation process $[12,13]$. Reasons for users to resist the implementation of an EMR are a poor design [14], too much pressure to adopt the EMR [15] or a lack of user involvement in the implementation process $[16,17]$. 
For implementation processes to be successful and to prevent adverse effects it is essential that one considers the interaction between all user groups, the organisation and the innovation. Taking account of potential differences in responses between the user groups increases the chance of a successful implementation of EMRs $[18,19]$.

We tried to construct a model that was based on knowledge in the literature and searched for operationalisations used in similar research. We build on the knowledge that the environment in which the innovation is adopted is essential for realisation of its potential [20]. An assumption in this paper is that a successful implementation of an EMR improves the quality of patient data. A new element of our study is that we investigate differences in responses to the EMRs between two user groups, doctors and nurses.

Aspects such as organisational culture and climate, leadership style, power balance and social relations [21] have been found to affect the uptake of innovations. When implementing an IT innovation the "soft" social and cultural aspects are as important as the "hard" technical and product specifications [22, 23]. Adding to the complexity is the fact that EMRs are used by different groups that need to work as a team and at the same time have different positions in the hospitals and can therefore be expected to react differently to organisational factors [24-27]. Implementation processes require users to change their work routines and they may be confronted with disadvantages including loss of autonomy [24, 28, 29]. Advantages and disadvantages may differ between user groups; their expectations may differ [30], their preferences may differ [31] and they may prefer different ways to use EMRs [32]. Taking account of the knowledge in the literature, and taking account of possible different reactions between user groups, we constructed a model that includes paths that lead from organisational factors to the outcome of the implementation process and the subsequent added value for its users in their daily routine [7], which ultimately affects the quality of patient data in the EMR. We hypothesise that the quality of the IT innovation is better if the quality of the organisational system is better and that this positively affect satisfaction of the user, EMR use and quality of patient data. This will affect both the individual and the organisational impact of the newly implemented system. We also expect that organisational factors are more important with regard to the successful implementation and use for nurses than for doctors. The main reason being that most medical specialists work in partnerships within hospitals, while nurses are employed by hospitals. The research question of this paper is: Which organisational factors affect the implementation success of the EMR as perceived by the user groups doctors and nurses most strongly and (on which aspects) does this differ between doctors and nurses?

\section{Methods}

\section{Questionnaire and data collection}

Doctors and nurses were invited to complete an on-line questionnaire if they worked in hospitals where an EMR was being implemented at the time of the data collection. The questionnaire contained items measuring the constructs of the theoretical model. The items in the questionnaire were based on previous research as much as possible. When needed, new items were developed (Additional file 1 presents the items). The constructs and links to theories are presented in the "Study variables" section.

The questionnaire was designed specifically for this study and used one time. The doctors and nurses were recruited from two separate research voluntary registries. The registry of the doctors contains physicians who volunteered to cooperate with studies by answering questionnaires. These volunteers were invited to participate in this study, explaining that is was a study on EMR use. The nurses were selected from a general research voluntary registry. In this registry nurses were selected based on their reported occupation. These nurses were invited to reply to the questionnaire similarly to the doctors. First, they were asked whether they currently worked with EMRs in their hospitals. Only those nurses who scored a "yes" on this question could participate in the present study. Both questionnaires were online for about two weeks. The respondents received a reward after completing the questionnaire,. Doctors received a monetary reward and the nurses were given "points" that enabled them to buy products. No reminders were sent.

\section{Analyses}

The data were analysed using Structural Equation Modelling (SEM), which combines path-analysis, simultaneousequation models and factor analysis [33, 34]. It enables estimating associations of latent variables (unobserved variables, measured with multiple items) and estimating multiple regression equations, including more than one dependent variable in one model. The results show the level of fit between the observed items and the latent variables. Regression parameters express the strength of the association between the latent variables. The evaluation of model fit is presented using three fit measures [35]: the RMSEA (Root Mean Square Error of Approximation), the CFI (Comparative Fit Index), and the TLI (Tucker Lewis Index). Each measure has to meet a particular threshold to indicate a good fit. We used the package 'lavaan' in R to conduct the analyses [33].

\section{Study variables}

The model that we built to test our hypotheses consists of four parts: Organisational aspects, Success of 
implementation, Decision of user and Result of using the EMR (Fig. 1 presents the model).

\section{Organisational aspects}

The social system that needs to adopt the innovation [8] is the hospital and the hospital contains a number of elements affecting the implementation process [36, 37]. There are several management tools and both "hard" organisational aspects and "soft" cultural and social aspects have been found to influence innovation $[6,21,22,37,38]$. In the following sections, we present the elements of the empirical model and literature of implementation research related to the subsequent elements.

Management tools The management of a hospital has several tools to guide organisational processes. Authentic leadership (Fig. 1) tends to affect other organisation members (e.g. clinicians) in that they legitimise management's role to guide the organisation [21, 39-41] and that they more readily accept organisational changes. Bottom-up influence is related to leadership and is known to affect the support of EMRs [16, 17, 41-43]. The model includes these two management tools. The precise wordings of the items are presented in the Additional file 1. Authentic leadership has a Cronbach's alpha of 0.92 and bottom-up communication has a Cronbach's alpha of 0.90 .

Support from other departments An other organisational aspect that we included in the model is support from other departments. Starting to work with an EMR requires new skills that need specific education and training during the implementation stage [44]. The HR department may help identifying these needs and offer targeted courses and training [21], thus improving the performance of the clinicians working with the EMR [45]. IT support may help to overcome practical problems. Hence, support from the IT department may play an important role during and after the implementation stage [46]. And because of the intrinsic link between EMR and administration, having administrative staff that supports users with entering patient data is likely to affect the successful implementation and use of an EMR [19]. The model includes three constructs for support from the IT, HR and administrative department. See the Additional file 1 for precise wordings. The Cronbach's alphas of the scales are 0.91 (IT department.), 0.90 (HR department) and 0.93 (administrative department).

Organisational culture A culture that enhances communication [47], or a culture that is innovative [48] and open $[21,42]$, is likely to contribute to the success of the implementation of EMR. We included two measures of culture: open culture and innovative culture, based on work of Woerkom [49] and de Jong et al. [50] respectively. The Cronbach's alphas are 0.70 for innovative culture and 0.76 for open culture.

\section{Success of implementation}

The success of implementation is measured with two items: ease of use and alignment with daily routine [51]. This notion is based on the Technology Acceptance

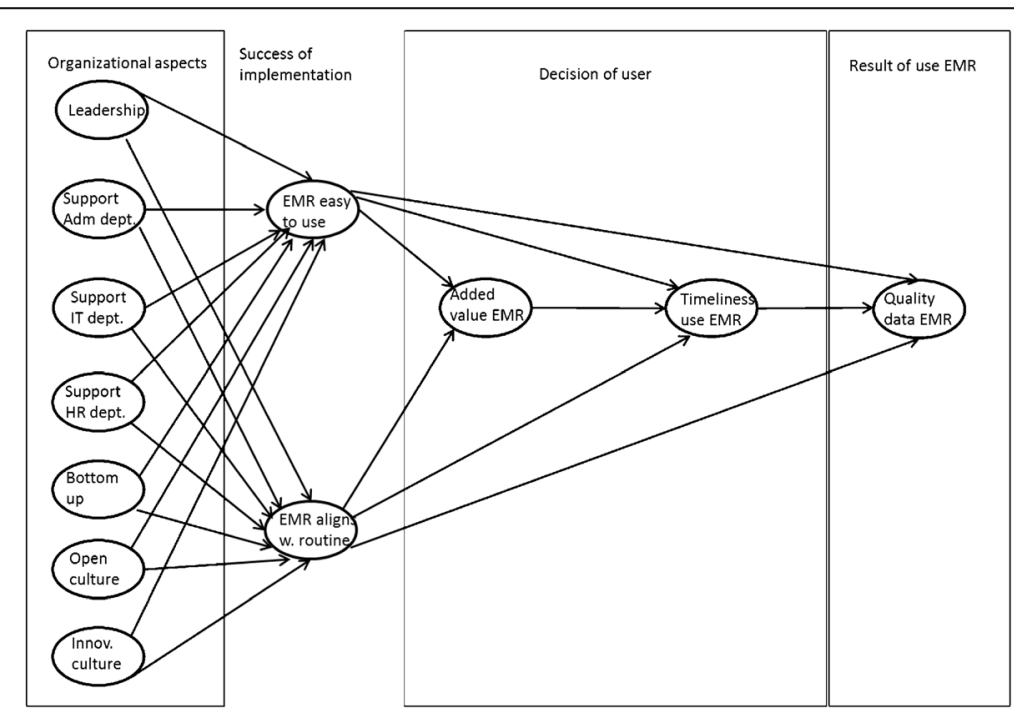

Fig. 1 Conceptual model (all expected signs of the paths are positive $(+)$ ). Leadership = authentic leadership; Support Adm dept $=$ support of administrative department; Support IT dept. = Support of IT department; Support of HR dept = Support of HR department; Bottom-up = Bottomup communication in the hospital; Cultopen = Open culture in hospital; Innov culture = Innovative culture in hospital; EMR easy to use = EMR is easy to work with; EMR aligns w. routine = Alignment of EMR to routine; Added value EMR = added value of EMR use by users; Timeliness use $E M R=$ Timeliness of entering patient data in EMR, reported by users; Quality data EMR = Quality of patient data in EMR) 
Model (e.g. [52]). The result of the EMR implementation is measured with two variables: ease of use and alignment with daily routine of the user groups [51]. The Cronbach's alphas are 0.87 and 0.92 respectively.

\section{Adoption decision by user}

When the added value of good quality patient data becomes clear to the user, the satisfaction with the system as well as its use are likely to increase [53]. We assume that the fit between technology, user and task affects the use of the innovation [5] in the sense that a better fit between daily routine and ease of use is likely to further the use of the innovation. We expect that ease of use and alignment of EMR to the daily routine will positively affect the perceived added value of EMR and that the users consequently will enter the patient data more timely in the EMR.

\section{Data quality in EMR}

The ultimate dependent variable, presented in Fig. 1 in the far right "result of use" section, represents the quality of the data in EMR as reported by its users (cf. organisational impact in [7]). It was assumed that if the data represents reality in terms of the patient's health and the care provided accurately and completely [54], its information will support the users (i.e. clinicians) in their work. Then the users will take full advantage of the potential of the EMR and it will support the organisation in process management, e.g. accurate billing [25].

Three factors are expected to influence quality of the data. First, by the way in which patient data are entered into the EMR (Fig. 1 section "Decision of user"). We assumed that the quality of the data is higher when the time between seeing the patient and entering the patient data is shorter. Second, when the EMR is easy to use, and this may be the result of a well-functioning implementation process, the quality of the data is higher. Third, a better alignment of the EMR functionalities and the daily routine of its users [14] is also expected to positively affect the quality of the data.

\section{Control variables}

The control variables are gender $(0=$ male and $1=$ female $)$, age and level of implementation of the EMR at the time of data collection. It is known that the implementation stage of the EMR affects the perception and support of users of EMRs $[55,56]$. The measurement of level of implementation is based on answers of respondents about computerisation of EMR in their hospital is (next to using paper files). The score is higher for respondents working with a completely computerised EMR. If the complete EMR was reported to consist of a single system, the score on this variable is higher $(+1)$, and if the EMR consists of multiple systems (and not one integrated system), the score is lower $(+0.5)$. When the data entered by nurses are visible to doctors and vice versa, the score of implementation level is also higher $(+1)$.

\section{Comparison of user groups}

The groups (doctors and nurses) are compared in two ways. First, we investigate whether the doctors and nurses differ in the regression parameters in differing from zero. Second, we compare significant differences of the regression coefficients between the groups by reestimating the multi group model, but constraining the regression parameters to be similar across groups. Subsequently, we ran models in which the parameter of interest was allowed to differ. Subsequently, the chi $^{2}$ change of the two models is compared. If the $\mathrm{chi}^{2}$ improves significantly, we conclude that the doctors and nurses differ in behaviour on this regression parameter. The differences in $\mathrm{chi}^{2}$ and subsequent significance levels are reported in the right hand columns of Table 2.

\section{Results \\ Sample}

474 doctors (24\%) and 699 (19\%) nurses returned the questionnaires. Only complete questionnaires were included. Due to item non-response, 914 respondents were included in the analyses (402 doctors and 512 nurses). Where possible, open answers were used to add to the closed questions, e.g. on the question of quality of the data. Sample characteristics are shown in Table 1. $17 \%$ of the nurses reported to work in an academic hospital, $22 \%$ in a top-clinical hospital, $50 \%$ in a general hospital, $3 \%$ in a specialized hospital, $7 \%$ in a mental hospital, and $1 \%$ in a private hospital. In the Netherlands, there are 85 hospitals, 8 of which are academic hospitals (9.4\%), and $90.6 \%$ are general or specialized hospitals. ${ }^{1}$ This means that in our respondent group, nurses and doctors from academic hospitals are overrepresented. This can be explained by the fact that we intended to include only nurses and doctors who had experience with working with EMR and that

Table 1 Sample characteristics

\begin{tabular}{lll}
\hline & Nurses (512) & Doctors (402) \\
\hline Mean age (SD) & $42.52(11.58)$ & $47.6(9.6)$ \\
\% female & $80 \%$ & $28 \%$ \\
Reported type of hospital & & \\
$\quad$ Academic & $17 \%$ & $24 \%$ \\
Top clinical & $22 \%$ & $30 \%$ \\
General & $50 \%$ & $41 \%$ \\
Specialized & $3 \%$ & $1 \%$ \\
Private & $1 \%$ & $2 \%$ \\
\hline
\end{tabular}


Dutch academic hospitals are at the forefront of implementing EMR.

\section{Analyses}

Table 2 and Fig. 2a,b and c present the main results of the analyses. Table 2 shows the regression coefficients of the multi group model for the two groups (doctors and nurses) and the analyses of the difference between the two groups. In the right columns, the $\mathrm{chi}^{2}$ difference with one degree of freedom is presented of a model with constraint regression parameters and a model with that particular regression parameter allowed to differ between the groups. If the difference is significant, this means that the nurses and doctors differ on this parameter. Figure 2a presents the SEM model for nurses and Fig. $2 \mathrm{~b}$ for doctors. Figure $2 \mathrm{c}$ presents the differences between the two groups. The solid arrows represent the significant regression paths and the dotted arrow the non-significant results. The multi group model (no constraints) has a good fit: $\mathrm{chi}^{2}(1966)=3852.62$; CFI $=0.93$; $\mathrm{TLI}=0.93$; $\mathrm{RMSEA}=0.046(95 \% \mathrm{CI}=0.044-0.048)$.

\section{Organisational factors and result of implementation}

Regression coefficients (reported in B and s.e.) and differences between the groups (the $\mathrm{chi}^{2}$ of model fit) in Table 2 show that nurses and doctors value the influence of organisational factors on the success of implementation differently. In line with the expectations, the doctors report that their EMR is easier to work with if there is more support from the administrative department $(B=0.15$, s.e. $=0.09)$, more support from the IT department $(B=0.22$, s.e. $=0.09)$, more bottom-up communication $(B=0.13$, s.e. $=0.05)$ and a more innovative culture $(B=0.19$, s.e. $=0.11)$. The nurses find their EMR easier to work with if there is more authentic leadership $(B=0.13$, s.e. $=0.07)$ and more support from the IT department $(B=0.37$, s.e. $=0.06)$ and bottom-up communication $(0.16$, s.e. $=0.05)$. The nurses find the EMR easier to work with when the culture is less open $(B=-0.21$, s.e. $=0.11)$ and when the culture is more innovative $(B=0.23$, s.e. $=0.10)$. The doctors and nurses differ in the influence of the support of the administrative department $\left(\right.$ chi $^{2}$ difference $=(4.39(1))$ and of the HR department $\left(\mathrm{chi}^{2}\right.$ difference $\left.=4.27(1)\right)$.

Doctors find the EMR to be better aligned with their daily routine if there is more authentic leadership $(B=0.31$, s.e. $=0.11)$ and more bottom-up communication in the hospital $(B=0.13$, s.e. $=0.06)$. The nurses find their EMR to be better aligned with their daily routine when they get more support of the IT department $(B=0.33$, s.e. $=0.07)$, but the HR department is negatively affect the alignment of the EMR $(B=-0.13$, s.e. $=0.05)$. In line with our expectations, nurses find the EMR better aligned with their work when there is more bottom-up communication $(B=0.19$, s.e. $=0.06)$ and an innovative culture $(B=0.27$, s.e. $=0.11)$.

\section{Success of implementation, added for value users and subsequent use}

The added value of the users of the EMR increases with easiness to work with and with alignment to their work for both doctors $(B=0.31$; s.e. $=0.04$ and $\mathrm{B}=0.76$; s.e. $=0.05$ respectively $)$ and nurses $(B=0.21$; s.e. $=0.04$ and $B=0.78$; s.e. $=0.05$ ).

\section{Quality of patient data}

Doctors find the patient data in the EMR of better quality when the EMR is easier to use $(B=0.27$, s.e. $=0.04)$. The nurses also find the quality of the patient data to be better when the EMR is easier to use $(B=0.13$, s.e. $=0.04)$ and nurses report that the quality of the data is better when the alignment to work is better $(B=0.17$, s.e. $=0.04)$. The doctors and nurses do not differ in these aspects.

Concerning the control variables, we see that doctors and nurses react differently to the level of implementation. This affects the nurses less than the doctors in their opinion on how it aligns with daily routine $\left(\mathrm{chi}^{2}\right.$ difference $=6.15$ (1)) and quality of the data $\left(\mathrm{chi}^{2}\right.$ difference $\left.=7.75(1)\right)$.

\section{Discussion}

This study aimed to increase our understanding of which organisational factors affect the success of implementation processes and how this may differ between doctors and nurses. We tried to construct a model that was based on knowledge in the literature and searched for operationalisations used in similar research. The body of literature is considerable and many competing theories and models exist. In many theories and models, the organisation, the innovation or technology and the user [1, 5-9] play a role. In many theories and models the purpose of an implementation process, i.e. to improve the status quo, remains more or less implicit, but we tried to include an outcome measure in the model: quality of the patient data. A new element of our study is that we applied the model to two different user groups (doctors and nurses) and found that they responded differently in a number of ways. Differences between stakeholders in implementation processes are acknowledged previously, but as far as we know, this is the first study to show that different user groups react differently to the same organisational aspects in an implementation process.

The most prominent differences between the doctors and the nurses are in their estimations of the influence of organisational support on implementation success. We find that the doctors and nurses differ in reaction to the support of the HR department. While the nurses tend to value $H R$ 
Table 2 Regression parameters of multi group SEM model, regression parameter reported separately for nurses, and doctors

\begin{tabular}{|c|c|c|c|c|c|c|c|c|}
\hline \multirow[b]{2}{*}{ Dependent variables } & \multirow[b]{2}{*}{ Independent variables } & \multirow{2}{*}{$\begin{array}{l}\text { Doctors } \\
b\end{array}$} & & \multirow[b]{2}{*}{ s.e. } & \multirow{2}{*}{$\begin{array}{l}\text { Nurses } \\
b\end{array}$} & & \multirow[b]{2}{*}{ s.e. } & \multirow{2}{*}{$\begin{array}{l}\text { Difference Doct/Nurse } \\
\text { Chi }^{2} \text { diff (1) }\end{array}$} \\
\hline & & & & & & & & \\
\hline & & & & & & & & Link with Fig. 1 \\
\hline \multirow[t]{8}{*}{ Easy to use } & & & & & & & & Organizational aspects and success of implementation \\
\hline & Leadership & 0.11 & & 0.10 & 0.13 & & 0.07 & 0.09 \\
\hline & Support administrative dept. & 0.15 & & 0.09 & -0.03 & & 0.07 & 4.39 \\
\hline & Support IT dept. & 0.22 & * & 0.09 & 0.37 & ** & 0.06 & 1.20 \\
\hline & Support HR dept. & 0.08 & & 0.05 & -0.05 & & 0.04 & 4.27 \\
\hline & Bottom-up options & 0.13 & * & 0.05 & 0.16 & ** & 0.05 & 0.23 \\
\hline & Open culture & -0.12 & & 0.16 & -0.22 & * & 0.11 & 0.50 \\
\hline & Innovative culture & 0.19 & & 0.11 & 0.23 & * & 0.10 & 1.21 \\
\hline \multicolumn{9}{|l|}{ Alignment with work } \\
\hline & Leadership & 0.31 & $* *$ & 0.11 & 0.09 & & 0.08 & 1.70 \\
\hline & Support administrative dept. & 0.07 & & 0.10 & -0.03 & & 0.08 & 0.62 \\
\hline & Support IT dept. & 0.15 & & 0.10 & 0.33 & $* *$ & 0.07 & 0.05 \\
\hline & Support HR dept. & 0.00 & & 0.06 & -0.13 & ** & 0.05 & 3.33 \\
\hline & Bottom-up options & 0.13 & $*$ & 0.06 & 0.19 & ** & 0.06 & 0.06 \\
\hline & Open culture & 0.17 & & 0.18 & -0.14 & & 0.12 & 2.09 \\
\hline & Innovative culture & 0.08 & & 0.12 & 0.27 & * & 0.11 & 0.57 \\
\hline & & & & & & & & Decision of user \\
\hline
\end{tabular}

Added value

$$
\begin{array}{llllllll}
\text { Easy to use } & 0.31 & * * & 0.04 & 0.21 & * * & 0.04 & 3.61 \\
\text { Alignment with work } & 0.76 & * * & 0.05 & 0.78 & * * & 0.05 & 0.71
\end{array}
$$

Timeliness of use

$\begin{array}{llllll}\text { Added value } & 0.05 & 0.11 & -0.04 & 0.16 & 3.64 \\ \text { Easy to use } & -0.07 & 0.06 & -0.14 & 0.08 & 3.58 \\ \text { Alignment with work } & -0.08 & 0.10 & 0.06 & 0.15 & 3.12 \\ & & & & & \text { Result }\end{array}$

Quality data

$\begin{array}{lllllllll}\text { Timeliness of use } & 0.02 & & 0.04 & -0.03 & & 0.03 & 0.67 \\ \text { Easy to use } & 0.27 & * * & 0.04 & 0.13 & * * & 0.04 & 2.57 \\ \text { Alignment with work } & 0.06 & & 0.04 & 0.17 & * * & 0.04 & 0.04\end{array}$

Quality data

$\begin{array}{llllllll}\text { Implementation stage } & 0.16 & * * & 0.05 & 0.01 & 0.04 & 7.75 \\ \text { Implementation stage } & 0.24 & * * & 0.04 & 0.05 & 0.04 & 6.15\end{array}$

Easy to use

Implementation stage $\quad 0.34 \quad * * 0.06 \quad 0.08 \quad * \quad 0.04 \quad 15.48$

Timeliness of use

$\begin{array}{llllll}\text { Age } & -0.01 & 0.00 & -0.01 & 0.01 & 0.51 \\ \text { Female } & 0.06 & 0.08 & 0.12 & 0.11 & 2.16\end{array}$

${ }^{* *}=p<0.01 ;{ }^{*}=p<0.05$

support negatively, the doctors appear to state that HR has little influence. The results of bottom-up communication are positive as expected for both user groups and when the EMRs are easier to use and better aligned with the work of the users, the added value is perceived to be higher.

We expected to find that clinicians who saw fewer benefits from working with the EMR would be more 

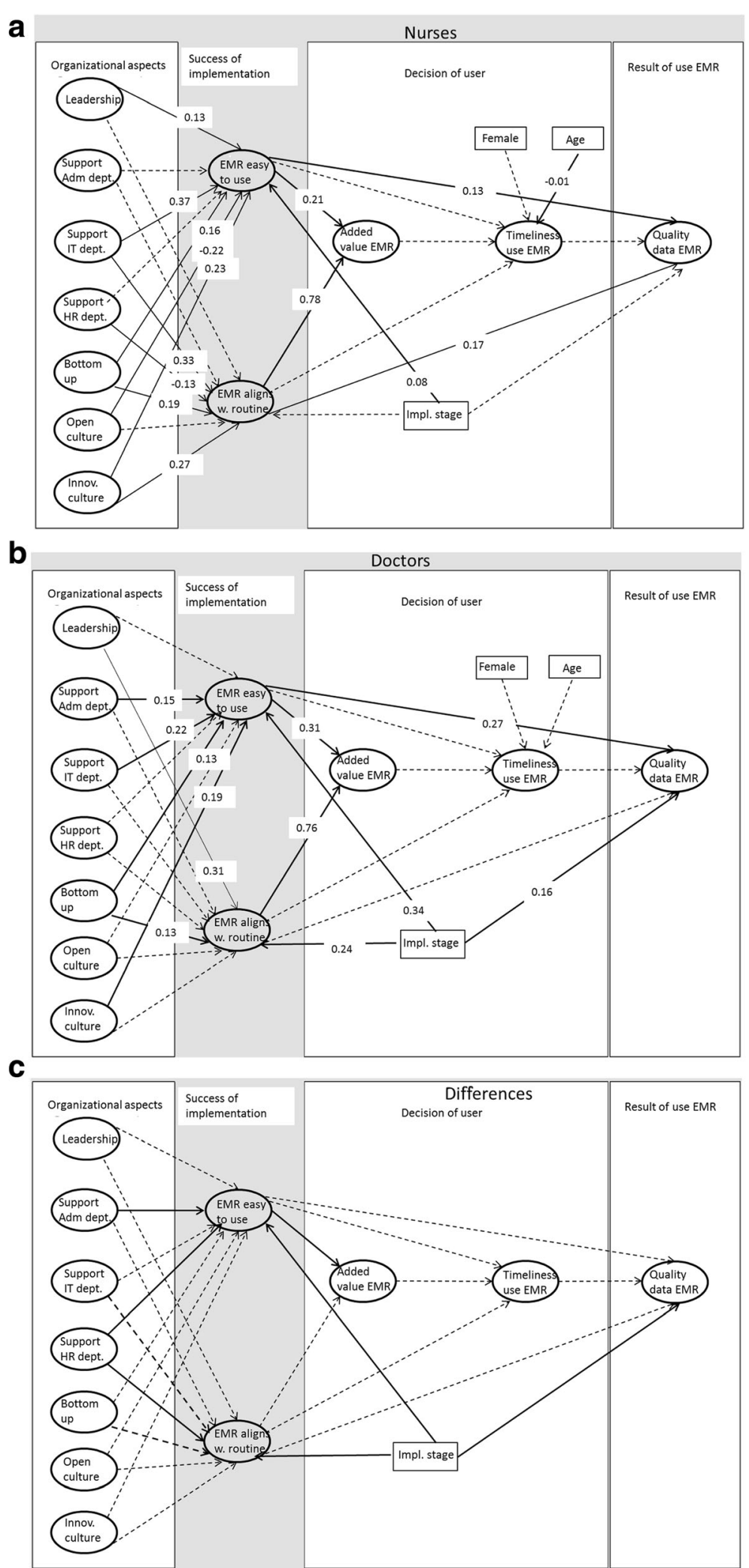

Fig. 2 (See legend on next page.) 
(See figure on previous page.)

Fig. 2 a Regression paths SEM model nurses. Leadership = authentic leadership; Support Adm dept = support of administrative department; Support IT dept. = Support of IT department; Support of HR dept = Support of HR department; Bottom-up = Bottom-up communication in the hospital; Cultopen = Open culture in hospital; Innov culture = Innovative culture in hospital; EMR easy to use $=E M R$ is easy to work with; EMR aligns w. routine $=$ Alignment of EMR to daily tasks; Added value EMR = added value of EMR use by users; Timeliness use EMR = Timeliness of entering patient data in EMR, reported by users; Quality data EMR = Quality of patient data in EMR). $\mathbf{b}$ Regression paths SEM model doctors. $\mathbf{c}$ Differences in responses between doctors and nurses. The solid arrow represent the paths of which the doctors and nurses differ (see table 3 far right column), dotted arrow represent paths with similar results for doctors and nurses

inclined to delay entering the patient data. However, organisational aspects were found to restrict much of the opportunities of the clinicians to hamper the use of the EMR. The characteristics of the result of the implementation are more closely associated with the use of the EMR. When the EMR is perceived as easy to use and is better aligned with their daily routines, less time elapses between the patient's visit and entering the patient data. The data indicate that doctors' opinions change stronger after working with the EMRs than the nurses', doctors tend to be more positive about how the EMR aligns with their routine and about quality of patient data. We did not find this for the nurses.

In this study, an innovative culture implies that colleagues and managers are inclined to consider new ideas to improve work processes. Interestingly, we found that an open culture, which is open to discussions on suboptimal performance, did not result in a better outcome of the implementation process. Contrary to expectations, nurses who had more opportunities to discuss problems with colleagues and management also found the EMR harder to work with. An explanation might be that in an innovative culture, the employees are encouraged to try new things, and not to dwell on what went wrong due to new working methods.

It should also be noted that the data used to investigate the measurement of the theoretical constructs relies on the perceptions of members of the organisation as they are reported by members of the organisation. This means that we did not investigate an 'objective' measure. Although such information is insightful, for example because organisational members have more confidence in projects if they believe that the management of their organisation can manage them appropriately, it should be acknowledged that these perceptions may not fully capture the actual situation in an organisation. This can be seen as a limitation, but may also be argued that the perceived situations (such as culture but also quality of the data) is what really affects the work processes of the doctors and nurses, more than the objective situation. If management for instance reports to ensure sufficient bottom-up communication, but doctors and nurses experience differently, measuring this parameter at the managerial level is not likely to enhance our understanding of the mechanisms that affect the use of innovations. Measurements of the factors in the model may be improved by combined views of more stakeholders and study where views overlap. Measurement of the quality of the data of EMRs can be measured even better since the files are stored and can be retrieved at a later moment in time. Therefore, improved measurements of the quality of data are for instance to retrospectively rate consistency and completeness of the patient files. This study shows that different actors react differently to the same organisational factors and future studies may focus on differences and similarities of perceptions of organisational factors and how these affect implementation processes.

We constructed the models based on the theoretical consideration presented in the introduction. First, we constructed the scales based on factor analyses. We confirmed the results with reliability analyses, to estimate the Cronbach's alpha of the scales. Next we built the model, assuming that organisational factors would affect the result of the implementation process and that in turn this would affect the response of the users and subsequent quality of use of the innovation. We took all organisational factors as a starting point without hypothesising on possible causation among these factors. It could also be argued for instance that leadership and bottom-up communication are enablers for the quality of practical support of the HR, IT and administrative departments. This could then maybe provide a mechanism to explain the effects of leadership and bottom up communication. However, given that both aspects also appear to have direct relations with the variables that indicate the success of the implementation, we assume that this model is sufficiently close to reality without having to add to the complexity of the model.

Given the relatively low response and the overrepresentation of respondents working in academic hospitals, the analyses may be biased to a certain extent. In general, academic centres are first to adopt novel techniques and people working in academic hospitals may be more inclined to use innovations than doctors and nurses in non-academic hospitals. By implication, in particular the variance in the attitudinal measure is lower than it would have been if the sample were representative on this parameter. Part of the lack of significance of the attitudinal variable may be that the respondents can do little else but to adopt an innovation that is implemented organisation-wide. 


\section{Conclusions}

Doctors and nurses differ in a number of aspects in their response to (new) use of EMRs. Bottom-up influence gave the most coherent results: for both doctors and nurses, the success of the innovation came with more bottom-up communication. A second relatively consistent finding is that support of the IT departments yields a positive result on EMR implementation. Doctors and nurses differ in their responses to the support of other department. Organisational culture had some influence but it seems to be less important and may work as a negative factor in use of EMRs.

By comparing the different factors that can influence the success of implementation, this study contributes to the scientific field of innovation and the implementation of new technology. We found indications that characteristics of the EMR (ease of use and alignment with tasks) have more influence on the quality of the data in the EMR than timely entering of patient data by the user groups.

For hospital managers, results of this study are directly applicable. Many of the actions they take, may result in differences in reactions from the user groups, sometimes in subtle but possibly relevant. However, when the users have bottom-up influence during and after the implementation process and when the IT department has the skills and ability to give optimal support to the users, this may positively affect the implementation success. In turn more successful the results of the implementation process, the better the quality of the data in the EMR, regardless of how timely the users enter the data into the system.

\section{Endnotes}

${ }^{1}$ http://statline.cbs.nl/StatWeb/publication/?DM=SLNL $\& \mathrm{PA}=81451$ ned $\& \mathrm{D} 1=0-2 \& \mathrm{D} 2=0-2 \& \mathrm{D} 3=\mathrm{a} \& \mathrm{HDR}=\mathrm{G} 1 \%$ 2CG2\&STB=T\&VW=T. Consulted May 82015

\section{Additional files}

Additional file 1: Latent constructs, manifest items, coding and factor loadings. Table with exact wording of questionnaire, factor loadings of items, ordered by scales, including Cronbach's alpha's. (DOCX 36 kb)

Additional file 2: Data of SEM model in CSV format. Raw data of included cases. The sex and age were removed on request by the journal for protection of privacy for the respondents. (CSV $102 \mathrm{~kb}$ )

Additional file 3: Codebook to the data. Variable names in the data and translated complete wording of items in questionnaire. Names of variables in Additional file 2 and the items in complete wording as presented in the Quesionnaire, translation from Dutch. (DOCX $19 \mathrm{~kb}$ )

Additional file 4: Complete Dutch questionnaire. (DOCX $25 \mathrm{~kb}$ )

\section{Abbreviations}

CFI: Comparative fit index; EMR: Electronic medical record; HR: Human resources; IT: Information technology; RMSEA: Root mean square error of approximation; SEM: Structural equation modelling; TLI: Tucker lewis index

\section{Acknowledgements}

The authors thank Iris Andriessen, Lidwien Lemmens, Koen vd Swaluw and Barbara Schooneveldt for their constructive comments and discussions on this paper.

\section{Funding}

This research was funded by the Strategic Research Program of the National Institute of Public Health and the Environment. The funding agency did not influence the study design, collection, analysis, and interpretation of data or decision to publish.

\section{Availability of data and materials}

Data are available as csv file in Additional file 2. The codebook to the data can be found in Additional file 3 and the original wording can be found in Additional file 4

\section{Authors' contributions}

$\mathrm{ML}$ initiated data collection and analyses, wrote substantial sections of the manuscript, HD co-wrote the manuscript and conclusions, FK assessed and improved the analyses and wrote sections of the manuscript. All authors read and approved the final manuscript.

\section{Competing interests}

The authors declare that they have no competing interests.

\section{Consent for publication}

Not applicable.

\section{Ethics approval and consent to participate}

According to The Dutch National Ethics Board (Central Committee on Research involving Human Subjects) formal testing by a medical ethical committee was not necessary, because the responding clinicians were asked to fill out 1) a single, anonymous survey that 2) did not include radical, incriminating or intimate questions, and 3) filling out the survey did not require much time. The respondents filled in the questionnaire on a voluntary basis after reading the explanation that the data would be used for scientific research by the National Institute of Health and the Environment. Consent was implied by completion of the questionnaire.

\section{Author details}

${ }^{1}$ Department Quality of care and health Economics, National Institute for Public Health and the Environment (RIVM), PO Box 13720 BA Bilthoven, The Netherlands. ${ }^{2}$ Department Quality of Care and Health Economics, National Institute for Public Health and the Environment (RIVM), Center for Nutrition, Prevention and Health Services, PO Box 13720 BA Bilthoven, The Netherlands. ${ }^{3}$ Department of Sociology, Erasmus University Rotterdam, Rotterdam and TIAS School for Business and Society, Tilburg, The Netherlands.

Received: 26 July 2016 Accepted: 3 February 2017

Published online: 10 February 2017

References

1. Chaudhry B, Wang J, Wu S, Maglione M, Mojica W, Roth E, Morton SC, Shekelle PG. Systematic review: impact of health information technology on quality, efficiency, and costs of medical care. Ann Intern Med. 2006;144:742-52.

2. Hillestad R, Bigelow J, Bower A, Girosi F, Meili R, Scoville R, Taylor R. Can electronic medical record systems transform health care? Potential health benefits, savings, and costs. Health Aff (Project Hope). 2005;24:1103-17.

3. Nambisan P, Kreps GL, Polit S. Understanding electronic medical record adoption in the United States: communication and sociocultural perspectives. Interact J Med Res. 2013;2:e5.

4. Boonstra A, Broekhuis M. Barriers to the acceptance of electronic medical records by physicians from systematic review to taxonomy and interventions. BMC Health Serv Res. 2010;10:231.

5. Ammenwerth $\mathrm{E}$, Iller C, Mahler C. IT-adoption and the interaction of task, technology and individuals: a fit framework and a case study. BMC Med Inform Decis Mak. 2006;6:3. 
6. Ancker JS, Kern LM, Abramson E, Kaushal R. The triangle model for evaluating the effect of health information technology on healthcare quality and safety. J Am Med Inform Assoc. 2012;19:61-5.

7. DeLone $\mathrm{WH}$, Mclean ER. Information systems success: the quest for the dependent variable. Inf Syst Res. 1992;3:60-95.

8. Rogers EM. Diffusion of Innovations, 4th Edition. New York: Simon and Schuster; 1995.

9. Grol R, Bosch MC, Hulscher MEJL, Eccles MP, Wensing M. Planning and studying improvement in patient care: the use of theoretical perspectives. Milbank Q. 2007;85:93-138.

10. Otieno GO, Hinako T, Motohiro A, Daisuke K, Keiko N. Measuring effectiveness of electronic medical records systems: towards building a composite index for benchmarking hospitals. Int J Med Inform. 2008;77:657-69.

11. Xue Y, Liang H, Wu X, Gong H, Li B, Zhang Y. Effects of electronic medical record in a Chinese hospital: a time series study. Int J Med Inform. 2012;81:683-9.

12. Petroll AE, Phelps JK, Fletcher KE. Implementation of an electronic medical record does not change delivery of preventive care for HIV-positive patients. Int J Med Inform. 2014;83:273-7.

13. Vishwanath $A$, Singh SR, Winkelstein $P$. The impact of electronic medical record systems on outpatient workflows: a longitudinal evaluation of its workflow effects. Int J Med Inform. 2010;79:778-91.

14. Babbott S, Manwell LB, Brown R, Montague E, Williams E, Schwartz M, Hess E, Linzer M. Electronic medical records and physician stress in primary care: results from the MEMO Study. J Am Med Inform Assoc. 2014;21:e100-6.

15. Ford EW, Menachemi N, Peterson LT, Huerta TR. Resistance is futile: but it is slowing the pace of EHR adoption nonetheless. J Am Med Inform Assoc. 2009:16:274-81.

16. Sassen EJ. Love, hate, or indifference: how nurses really feel about the electronic health record system. Comput Inform Nurs. 2009;27:281-7.

17. Lium JT, Tjora A, Faxvaag A. No paper, but the same routines: a qualitative exploration of experiences in two Norwegian hospitals deprived of the paper based medical record. BMC Med Inform Decis Mak. 2008;8:2.

18. Sykes TA, Venkatesh $V$, Rai A. Explaining physicians' use of EMR systems and performance in the shakedown phase. J Am Med Inform Assoc. 2011:18:125-30.

19. Miller RH, Sim I. Physicians' use of electronic medical records: barriers and solutions. Health Aff. 2004;23:116-26.

20. Deuten JJ, Rip A, Jelsma J. Societal embedding and product creation management. Technol Anal Strateg Manag. 1997:9:131-48.

21. Greenhalgh T, Robert G, Macfarlane F, Bate P, Kyriakidou O. Diffusion of innovations in service organizations: systematic review and recommendations. Milbank Q. 2004;82:581-629.

22. Greenhalgh T, Morris L, Wyatt JC, Thomas G, Gunning K. Introducing a nationally shared electronic patient record: case study comparison of Scotland, England, Wales and Northern Ireland. Int J Med Inform. 2013; 82:e125-38.

23. Pare G, Raymond L, de Guinea AO, Poba-Nzaou P, Trudel MC, Marsan J, Micheneau T. Barriers to organizational adoption of EMR systems in family physician practices: a mixed-methods study in Canada. Int J Med Inform. 2014;83:548-58.

24. McGinn CA, Grenier S, Duplantie J, Shaw N, Sicotte C, Mathieu L, Leduc Y, Legare F, Gagnon MP. Comparison of user groups' perspectives of barriers and facilitators to implementing electronic health records: a systematic review. BMC Med. 2011:9:46.

25. Holden RJ. Physicians' beliefs about using EMR and CPOE: in pursuit of a contextualized understanding of health IT use behavior. Int J Med Inform. 2010;79:71-80

26. Myers JJ, Koester KA, Chakravarty D, Pearson C, Maiorana A, Shade SB, Steward WT. Perceptions regarding the ease of use and usefulness of health information exchange systems among medical providers, case managers and non-clinical staff members working in HIV care and community settings. Int J Med Inform. 2012;81:e21-9.

27. McGinn CA, Gagnon MP, Shaw N, Sicotte C, Mathieu L, Leduc Y, Grenier S, Duplantie J, Abdeljelil AB, Legare F. Users' perspectives of key factors to implementing electronic health records in Canada: a Delphi study. BMC Med Inform Decis Mak. 2012;12:105

28. Laerum H, Karlsen TH, Faxvaag A. Use of and attitudes to a hospita information system by medical secretaries, nurses and physicians deprived of the paper-based medical record: a case report. BMC Med Inform Decis Mak. 2004:4:18.
29. Noblin A, Cortelyou-Ward K, Cantiello J, Breyer T, Oliveira L, Dangiolo M, Cannarozzi M, Yeung T, Berman S. EHR implementation in a new clinic: a case study of clinician perceptions. J Med Syst. 2013;37:9955.

30. Lambooij MS, Hummel MJ. Differentiating innovation priorities among stakeholder in hospital care. BMC Med Inform Decis Mak. 2013;13:91.

31. Struik MH, Koster F, Schuit AJ, Nugteren R, Veldwijk J, Lambooij MS. The preferences of users of electronic medical records in hospitals: quantifying the relative importance of barriers and facilitators of an innovation. Implement Sci. 2014;9:69.

32. Ancker JS, Kern LM, Edwards A, Nosal S, Stein DM, Hauser D, Kaushal R. How is the electronic health record being used? Use of EHR data to assess physician-level variability in technology use. J Am Med Inform Assoc. 2014:21:1001-8.

33. Roseel Y. Lavaan: an R package for structural equation modeling. J Stat Softw. 2012:48:1-36.

34. Jöreskog KG, Sörbom D. Advances in factor analysis and structural equation models. New York: University Press of America; 1979.

35. Schumacher RE, Lomax RG. A beginner's guide to structural equation modeling. Hilsdale: Lawrence Erlbaum; 1996.

36. Chaudoir SR, Dugan AG, Barr CHI. Measuring factors affecting implementation of health innovations: a systematic review of structural, organizational, provider, patient, and innovation level measures. Implement Sci. 2013;8:22.

37. Grol R, Grimshaw J. From best evidence to best practice: effective implementation of change in patients' care. Lancet. 2003;362(9391):1225230.

38. Grol R, Wensing M. Implementatie, effectieve verbetering van de pati ل'ntenzorg. Amsterdam: Reed Business; 2011.

39. Bass BM. Handbook of leadership; theory, research and managerial applications. New York: Free Press; 2008.

40. West MA, Borrill CS, Dawson JF, Brodbeck F, Shapiro DA, Haward B. Leadership clarity and team innovation in health care. Leadersh Q. 2003;14: 393-410.

41. Paré G, Sicotte C, Poba-Nzaou P, Balouzakis G. Clinicians' perceptions of organizational readiness for change in the context of clinical information system projects: insights from two cross-sectional surveys. Implement Sci. $2011 ; 6$.

42. Nemeth LS, Feifer C, Stuart GW, Ornstein SM. Implementing change in primary care practices using electronic medical records: a conceptual framework. Implement Sci. 2008;3:3.

43. Edwards $C$. Nursing leaders serving as a foundation for the electronic medical record. J Trauma Nurs. 2012;19:111-4. quiz 115-116.

44. Whitten $P$, Buis $L$, Mackert M. Factors impacting providers' perceptions regarding a midwestern university-based EMR. Telemed J E Health. 2007;13:391-7.

45. Taft T, Lenert L, Sakaguchi F, Stoddard G, Milne C. Effects of electronic health record use on the exam room communication skills of resident physicians: a randomized within-subjects study. J Am Med Inform Assoc. 2015;22:192-8.

46. Kraatz AS, Lyons CM, Tomkinson J. Strategy and governance for successful implementation of an enterprise-wide ambulatory EMR. J Healthc Inf Manag. 2010;24:34-40

47. Reynolds K, Nowinski C, Becker S, Beaumont J. Organizational culture changes in an integrated delivery system with a fully implemented electronic medical record. AMIA Annu Symp Proc. 2006:1075. PMC1839303.

48. Retchin SM, Wenzel RP. Electronic medical record systems at academic health centers: advantages and implementation issues. Acad Med. 1999:74:493-8.

49. van Woerkom M. Critical reflections at work. Bridging individual and organizational learning. Enschede: Printpartners Ipskamp; 2003.

50. de Jong JPJ, den Hartog DN. Determinants of innovative behaviour: research on knowledge workers in SME (Determinanten van innovatief gedrag: een onderzoek onder kenniswerkers in het MKB). Gedrag Organisatie. 2005;18:235-59.

51. Davis FD. Perceived usefulness, perceived ease of use, and user acceptance of information technology. Manag Inf Syst Q. 1989;13:319-40.

52. Venkatesh V, Morris MG, Davis GB, Davis FD. User acceptance of information technology: toward a unified view. MIS Q. 2003;27:425-78.

53. Kimiafar K, Sadoughi F, Sheikhtaheri A, Sarbaz M. Prioritizing factors influencing nurses' satisfaction with hospital information systems: a fuzzy analytic hierarchy process approach. Comput Inform Nurs. 2014;32:174-81.

54. Jang J, Yu SH, Kim CB, Moon Y, Kim S. The effects of an electronic medical record on the completeness of documentation in the anesthesia record. Int J Med Inform. 2013;82:702-7. 
55. El-Kareh R, Gandhi TK, Poon EG, Newmark LP, Ungar J, Lipsitz S, Sequist TD. Trends in primary care clinician perceptions of a new electronic health record. J Gen Intern Med. 2009;24:464-8.

56. McMurray J, Hicks E, Johnson H, Elliott J, Byrne K, Stolee P. Trying to find information is like hating yourself every day': the collision of electronic information systems in transition with patients in transition. Health Informatics J. 2013;19:218-32.

Submit your next manuscript to BioMed Central and we will help you at every step:

- We accept pre-submission inquiries

- Our selector tool helps you to find the most relevant journal

- We provide round the clock customer support

- Convenient online submission

- Thorough peer review

- Inclusion in PubMed and all major indexing services

- Maximum visibility for your research

Submit your manuscript at www.biomedcentral.com/submit
Biomed Central 